\title{
Participación ciudadana y democracia experimentalista: El control social a la gestión pública a 23 años de la promulgación de la Constitución Política de Colombia
}

\author{
Experimentalist citizen participation and democracy: \\ The social control of public administration and 23 years \\ after the promulgation of the Constitution of Colombia \\ Participação dos cidadãos e a democracia experimentalista: \\ O controle social à gestão pública a 23 anos da promulgação \\ da Constitução Politica da Colômbia
}

\begin{abstract}
RESUMO
Este artigo registra a linha de resultados dos artigos de pesquisa realizada no desenvolvimento do projeto de tesis da mestria do autor, que com metodologia qualitativa e quantitativa fezuma abordagem ao jeito da apropriação dos cidadãos de mecanismo de compartilhamento e ocontrole social, establecidos como principios fundamentais da Constitução política da Colômbia de 1996. Tomado como caso de estudo do bagre (A pesquisa conlui fazendo uma análise na democracia experimentalista e as variantes conflitantes que assume no local como uma proposta alternativa do direito horizontal, participativo, consensual e deliberativo.
\end{abstract}

PALABRAS-CHAVES

Participação dos cidadãos, Controle social, Democracia experimentalista, Governança, Stakeholders, Políticas públicas.

\section{RESUMEN}

El presente artículo se inscribe en la línea de artículo resultado de investigación realizado en el desarrollo del proyecto de tesis de Maestría del autor, que con metodologías cualitativas y cuantitativas hizo un abordaje al tema de la apropiación ciudadana de mecanismos de participación y el control social, establecidos como principios fundamentales de la Constitución Política de Colombia de 1991. Se toma como caso de estudio de El Bagre (Bajo Cauca antioqueño). La investigación concluye haciendo un análisis en la democracia experimentalista y las variantes conflictivas que esta asume en lo local como una propuesta alternativa del derecho horizontal, participativo, consensuado y deliberativo.

PALABRAS CLAVE

Participación ciudadana, Control social, Democracia experimentalista, Gobernanza, Stakeholders, Políticas públicas.

\begin{abstract}
This article is part of the line item result of research conducted in developing the project master thesis of the author, with qualitative and quantitative methodologies I make an approach to the issue of public ownership of mechanisms for participation and social control, it established as fundamental principles of the Constitution of 1991. Colombia is taken as a case study Catfish (Bajo Cauca antioquia). The research concludes with a review of the experimentalist democracy and conflicting variants it assumes in the local as an alternative proposal of horizontal, participatory, deliberative and consensual right.
\end{abstract}

KEYWORDS

Citizen participation, Social control, Experimentalist democracy, Governance, Stakeholders, Public policy.

\section{EDUIN TAMAYO GUISAO}

Magíster en Desarrollo Social de la Universidad Pontificia Bolivariana de Medellín. Se desempeña como profesional de la Contraloría General de la República en el área de Participación Ciudadana de la Gerencia Departamental Antioquia, donde es responsable de adelantar en los 125 municipios del departamento procesos de promoción de la participación ciudadana y el control social. Este trabajo es un resumen de su investigación sobre participación ciudadana y control social en El Bagre, Antioquia.ejtamayo@contraloria.gov.co 


\section{INTRODUCCIÓN}

-¿Qué quieres saber ahora? -pregunta el guardián-. Eres insaciable. Todos se esfuerzan por llegar a la Ley-dice el hombre-; ¿cómo es posible entonces que durante tantos años nadie más que yo pretendiera entrar? El guardián comprende que el hombre está por morir, y para que sus desfallecientes sentidos perciban sus palabras, le dice junto al oído con voz atronadora: -Nadie podía pretenderlo porque esta entrada era solamente para ti. Ahora voy a cerrarla (Kafka, 1983, p. 1133).

La realidad colombiana puede ejemplificar el problema de los ríos desbocados de la fuerza directa del demos. Seis años después de promulgada la Constitución Política colombiana de 1991, exactamente el 6 de junio de 1997, en el departamento de Nariño, municipio de Barbacoas, el frente 29 de las Farc (con más de 200 integrantes), a las 2:50 de la madrugada, atacó con tiros de mortero la estación de policía resguardada por un total de 13 uniformados, quienes resistieron el combate hasta que se les agotó la munición a las 8 de la mañana. Los policías, superados en número y armamento, después de haber resistido lanzacohetes, 24 granadas, y más de 6.010 tiros de fúsil, se rindieron con un saldo de 4 agentes muertos, un suboficial y 3 agentes heridos.

Los policías sobrevivientes fueron obligados por la guerrilla a tenderse en el piso y justo cuando iban a ser ejecutados con tiros de gracia, una habitante del pueblo conocida como "Kola y Pola" (cuyo nombre verdadero era Apolicenia Angulo), en aparente estado de ebriedad, se interpuso entre los policías y la guerrilla, increpando a los guerrilleros a que respetaran la vida de los uniformados. Uno de los guerrilleros le solicitó que se retirara, pero Apolicenia se resistió golpeando en la cara con una botella a una mujer guerrillera, quien sin mediar palabra la mató de una ráfaga de fusil.

Nuevamente los agentes se encontraban a punto de ser asesinados, pero el comandante del Frente decidió reconocerlos como héroes dada la resistencia que presentaron, por lo que ordenó que se desnudaran y salieran del pueblo. En su salida, pudieron observar cómo el pueblo al que habían protegido por más de cinco horas, se dio a la tarea de destruir el Comando de la Policía, robar sus pertenencias, quemar el archivo y saquear la Caja Agraria. Uno de los agentes implicados señalaba en sus declaraciones, con lágrimas en los ojos, que no entendía cómo "estaba ofreciendo su vida por un pueblo que no aceptaba la mano del Estado" (Consejo de Estado, 2013).

Si se aplica una lectura metafórica de estos hechos, se podrán encontrar varios elementos: un pueblo que busca su propio beneficio, un Estado débil incapaz de entender lo que ocurre a su alrededor y una locura que exige lo justo y por lo tanto es asesinada. Analizando la historia de Colombia, es factible argumentar que es una tradición acallar la locura 
de la justicia y en ocasiones el demos embravecido, lucha anómicamente por instaurar y preservar el mundo de lo alterlegal. Esta historia dura y cruel se puede explicar en el contexto de un país dual, una Colombia que funciona en el centro, pero que es disfuncional en la periferia (Robinson, 2014).

En este marco de reflexión, la participación ciudadana, la gran utopía fundacional de la democracia, se encuentra inmersa en una crisis que, desde los cimientos mismos de la ética democrática, amenaza con colapsar. Ciudadanía, contrato social y empoderamiento comunitario son hoy declaraciones y enunciados difíciles de materializar.

Asistimos como observadores desconcertados al nuevo escenario global de acciones colectivas. De los movimientos sociales tradicionales damos paso a cibermovimientos y acciones colectivas fragmentarias (Ocupy en Wall Street, Okupas en Europa, Emputados en Colombia), del concepto de Estado-nación pasamos al de mundialización y del Derecho duro pasamos al Derecho suave (soft law). El poder blando (soft power) se erige como modelo de reivindicación colectiva y de acuerdos sociales (Martel, 2011).

Evidenciamos en el nuevo escenario global cómo los fenómenos de participación ciudadana y de empoderamiento de la sociedad civil están tomados de la mano de grandes procesos de democratización a nivel global (De Souza Santos, 2005). Estos procesos pueden terminar siendo un nuevo disfraz que asume la dominación hegemónica de los sistemas de representación política y de su ente legitimador: la democracia participativa. En este sentido, se puede precisar que:

En los últimos años las sociedades modernas han sido testigo del debilitamiento del modelo contractualista que se ha expresado en la emergencia de una lógica individualizada que restringe la intervención del Estado y que promueve la generación de contratos civiles, en un juego de competencia, que ha producido el debilitamiento del clásico modelo moderno, así como la generación de nuevas exclusiones. Las transformaciones que ha generado este proceso de debilitamiento y cambio, han sido la construcción de nuevos consensos económicos, políticos y democráticos. Ante este panorama se ha logrado erigir un nuevo mecanismo democrático para transformar la contractualidad moderna en un nuevo pacto que esté acorde con las exigencias del mundo postmoderno; ese nuevo componente del cambio social, político y económico es la democracia participativa (Guevara Salamanca, 2009, pp. 1-2).

De igual forma, las implicaciones globales se viven en los contextos locales. De ahí que en Colombia, particularmente en el municipio El Bagre, en concordancia con las tendencias globales, se observa una fragmentación de lo público y una lógica capitalista hegemónica que se apropia de los procesos de control sobre lo público. 
De esta manera se identifican situaciones, actores y sujetos que en el nivel territorial propician caracterizaciones y análisis sobre problemáticas relacionadas con aspectos constitucionales y legales, que autorizan el control social, pero que en la práctica social y territorial, en el municipio, no se expresan en condiciones para iniciar, desarrollar y evaluar políticas de control social a la gestión pública. Particularmente sobre este aspecto Velásquez afirma que:

Existe hoy en algunos sectores de la población una cierta sensación de frustración con la participación ciudadana en Colombia [...] Ese desencanto se refiere no solamente al proceso mismo, sino a los resultados. Al proceso, en el sentido de que los líderes sienten que su trabajo ha servido poco pues su participación ha tenido escasa incidencia en las decisiones locales (2003, p. 259).

En este contexto, y desde lo que promulga la Constitución Política de Colombia de 1991, es posible evidenciar una contradicción entre las formas en que se ejecutan la gestión pública y los derechos de participación ciudadana para el control social. En estas se evidencian exclusiones y señalamientos de las iniciativas de control social y de los actores territoriales y municipales que los promueven.

En igual sentido, en el municipio donde se enfocó la investigación, son pocas las evidencias que permiten observar el acompañamiento de la institucionalidad pública, en relación con la conformación acción y sostenibilidad de iniciativas de control social. En consecuencia, resulta pertinente indicar que la participación ciudadana en el control social no representa un factor estratégico para propiciar escenarios de democracia participativa en la región.

Por ende, el proceso de investigación científica diseñado concentró la atención en el ámbito de la participación ciudadana y el control social a la gestión pública en calidad de caso de estudio en el Bajo Cauca antioqueño, siendo el municipio seleccionado El Bagre.

Particularmente la población de estudio estuvo focalizada en las veedurías ciudadanas (organizaciones que propician control social a la gestión pública), en los ciudadanos que participaron en actividades de control social en las fechas del estudio y en las organizaciones e instituciones (funcionarios públicos y privados) que están directamente implicados en las actividades de control social y participación ciudadana.

En este sentido, este artículo da cuenta de los hallazgos sobre la opinión pública de la democracia y su relación con las fuertes tendencias de la democracia experimentalista en contextos locales.

\section{ANÁLISIS SOBRE LA PARTICIPACIÓN CIUDA- DANA EN EL BAGRE: OPINIÓN PÚBLICA Y DEMOCRACIA}

Hace diez años abrigábamos la esperanza de que la democracia participativa fuese 
algo así como la clave que abriría todas las puertas bloqueadas por siglos de exclusión y de abandono [...] Hoy predomina el desencanto y un sentimiento vago de cansancio (Uribe, 2002, p. 191).

Tal vez, un resumen clave y actualizado de cómo podemos interpretar la realidad colombiana y sus devenires locales lo encontramos en Acemoglu y Robinson, quienes describen dos interpretaciones paradigmáticas que han tratado de explicar las manifestaciones locales de precariedad institucional. Partiendo de estos lugares comunes en los discursos académicos, se logra proponer una nueva forma de entendernos que podríamos contextualizar en la concepción teórica del neoinstitucionalismo (Acemoglu y Robinson, 2012).

La primera de estas visiones es ya tradicional, la que Robinson (2014, pp. 15-16) caracteriza como la visión conservadora, donde el devenir histórico de nuestra nación no es más que un simple producto de la "mala suerte", dado que como país simplemente tenemos una geografía abrupta y el mal del destino denominado ethos violento. Esta mirada considera que circunstancias difíciles de superar, así como la mala suerte, son los demonios históricos que no hemos podido exorcizar (niega esta concepción que países con iguales dificultades y con peores conflictos no obtuvieron los mismos resultados que Colombia).

El segundo paradigma es el que se entiende como "La lectura de la modernización radical/bloqueada" (Robinson, 2014, p. 16). Esta entrega toda la responsabilidad de nuestra historia truncada al inacceso del Estado y a la imposibilidad de una construcción de ciudadanía. En este marco analítico, se señalan como únicos culpables a los partidos políticos, quienes bloquearon la modernidad y monopolizaron el Estado, repartiendo sus riquezas, controlando elecciones y produciendo altas cuotas de violencia contra la oposición.

Paradójicamente, esta visión trata de negar la tradicional e histórica fe en la democracia que representa la institucionalidad colombiana en el contexto latinoamericano, pero sobre todo, lo radical de esta interpretación estriba en la no creencia en la democracia, ya que considera que esta es de muy baja calidad (la famosa frase, de que Colombia es una democracia que se parece a un "orangután con sacoleva").

Ante estas dos miradas tradicionales y excluyentes, se plantea una perspectiva mucho más cercana con la realidad de un "Estado alertado" (Foreing Policy, 2014), la que Robinson titula como "La lectura de la sociedad dual en Colombia". En palabras de este autor, asistimos a una dualidad entre el centro institucional del país y su periferia:

Colombia tiene una tradición de solidez democrática e institucional paralela a la guerra civil y al negocio de la droga debido a la manera particular en que el Estado 
colombiano se formó históricamente y se relacionó con su territorio y sus ciudadanos. Las elites nacionales en Bogotá jamás se propusieron controlar o regular vastas zonas del país, y en cambio delegaron dicha tarea a las elites locales, a cambio de votos en las elecciones. Esto generó una particular articulación geográfica del Estado, de los servicios estatales y del desarrollo. Hay un centro del país donde el Estado está más presente, las leyes y normas mejor ejecutadas y en el que hay menos pobreza; y hay una gran periferia en la que ocurre todo lo contrario. Tal periferia incluye la costa Caribe, los Llanos Orientales, el litoral Pacífico y las selvas y montañas del sur. La solidez institucional de Colombia se da en el centro. Si hay que hacer algo en Bogotá por medio de la Corte Constitucional o el Banco de la República, entonces puede funcionar. Si es necesario hacerlo en la periferia, como la reforma agraria, no funcionará. Parte de la clave para entender cómo lo funcional y lo disfuncional coexisten está en entender que los dos están espacialmente diferenciados. Que lo disfuncional esté en la periferia significa que el dolor y el caos que genera se concentran a gran distancia de las elites nacionales (p. 18).

Dicho de otra manera, somos legales cuando es imposible escapar de la legalidad. De lo contrario no creemos en la institucionalidad, no confiamos en los políticos y no depositamos confianza en los entes de control, la política o los medios masivos de comunicación.
Los resultados de la última gran encuesta sobre confianza en las instituciones revelan de forma dramática esta dualidad y la ausencia casi total de confianza entre el ciudadano y las instituciones (Revista Semana, 2014).

El $77 \%$ de los colombianos encuestados cree que la justicia no está haciendo lo correcto, el $73 \%$ declara desconfianza en las altas Cortes y en el rol que juegan en el desarrollo del país. Existe una percepción negativa del $60 \%$, en la Corte Suprema de Justicia; del $57 \%$ en la Corte Constitucional y del $75 \%$ en el Senado y la Cámara, sobre estos dos últimos, el pueblo colombiano no confía en su trabajo ni en sus funciones. En cuanto a los entes de control, el $60 \%$ no cree en el trabajo de la Contraloría de la República y el $60 \%$ no confía en el trabajo de los medios de comunicación.

La muerte de la política y su pasividad se evidencia en que el $70 \%$ de los encuestados precisó tener una imagen desfavorable de los partidos, los peor evaluados en este sentido son: Cambio Radical con un $77 \%$, el Centro Democrático y el Partido Verde con 72 \% de imagen desfavorable, y el Partido Liberal con un $71 \%$.

Lo preocupante de la crisis de los partidos es una tendencia a largo plazo que está tomando fuerza: la no filiación partidista, la cual aparece con un porcentaje de $38 \%$ de encuestados que afirman no pertenecer a ningún partido político. La paradoja colombiana entre el optimismo y el no optimismo reduce 
sus diferencias: los que creen que el país va por buen camino y los que opinan lo contrario se centra en tan solo un $5 \%$ de diferencia -ya que el $45 \%$ afirma que el país va por un buen camino-; no podemos olvidar que Colombia sigue siendo considerado el país más feliz del mundo (Gallup, 2013).

En este punto, es pertinente anotar que el municipio en estudio representa una expresión local de lo que se ha explicado como dualidad (Robinson, 2014), es decir, un país que funciona institucionalmente en el centro, pero que es disfuncional en la periferia, una institucionalidad fuerte en las urbes más pobladas y con mayor desarrollo y una institucionalidad débil en el ámbito rural, que es distante y por lo general atrasado en necesidades básicas. De ahí que Colombia sea un clásico Estado que, como se ha mencionado anteriormente, posibilita zonas alterlegales.

La versión neoinstitucionalista plantea que las élites de poder particularmente se estructuran generando grupos in y grupos out. Los grupos in producen cercanía social y se integran en la defensa de sus intereses, los grupos out son los que están fuera del círculo de intereses de los grupos in, son distanciados con estrategias de cooptación institucional. Estas metodologías propias de las élites se ven dinamizadas conflictualmente por dos factores exógenos que tienden a polarizar las fuerzas en acción. El primero de ellos es la fragmentación de las élites que luchan entre sí por la cooptación institucional, de ahí que el acceso al Estado esté mediatizado por di- versos grupos familiares que entran en alianzas (que funcionan con metodologías empresariales) para apoderarse de los recursos del Estado.

El segundo factor es el clientelismo y la corrupción asociados a la feudalización de las diversas expresiones institucionales del Estado. Es común señalar que tal institución del Estado pertenece a un personaje en particular, es decir, las instituciones tienen dueños y el acceso a los beneficios depende de la voluntad de los propietarios de facto, que a través de contratos y prebendas tienden a preservarse en el poder.

En correlación con los datos antes mencionados, esta dualidad y la incidencia de las élites fragmentadas, la podemos evidenciar en la información empírica que arroja el análisis de la percepción de la democracia y de la percepción de la representatividad realizado en El Bagre. Entiende esta encuesta cuantitativa que la opinión pública sobre la democracia implica una percepción, una forma de sentir la democracia, pero también una forma de cómo se interviene en la misma. En palabras de Marta Lagos (Domínguez y Shifter, 2005):

El contenido de la palabra democracia, si tomamos las palabras como productos mentales para la mayoría de los entrevistados, no es el concepto complejo empleado por los analistas, sino tan solo la suma de experiencias interactivas en una cultura determinada. El contenido de la palabra "democracia" está determinado 
culturalmente; de hecho, es una percepción. Las encuestas de opinión pública miden las percepciones y las percepciones son verdad, porque la gente las cree. Una percepción como producto mental puede ser verdadera o falsa cuando se mide contra un indicador objetivo, no obstante esto no cambia el contenido de la verdad creída (p. 157).

De ahí que la encuesta se aproximó a una comprensión estadística de las percepciones asociadas con democracia, participación ciudadana y confianza en las instituciones. Para asumir un compendio holístico con mayor rigurosidad epistémica, se asociaron a las respuestas cuantitativas, las subjetividades de los actores sociales. En este sentido, se procesaron entrevistas a líderes representativos de la comunidad, los cuales se integran durante el proceso de análisis de los datos estadísticos. Todo ello posibilita confirmar el análisis central del trabajo: la crisis de representatividad, que deviene en una crisis institucional, la cual emana del proceso de conversión del ciudadano a cliente. En todo el análisis cuantitativo y cualitativo que sigue a continuación se demuestra la dualidad de la sociedad colombiana, pero especialmente las manifestaciones de esta dualidad en el plano de lo local-periférico.

En El Bagre, la confianza en las instituciones está tomada de la mano con los datos nacionales. El $46 \%$ de la muestra señala tener una percepción favorable de la Personería, el 50,7 \% afirma tener una percepción favorable de la
Procuraduría, el 50,3 \% plantea favorabilidad en cuanto al trabajo de la Contraloría, el $43 \%$ ve favorable la labor de la Defensoría y el $45,7 \%$ entiende como favorable la acción de la Fiscalía. Se concluye que hay una percepción mediana en las instituciones y en su poder efectivo de control.

Esto da la idea de que existe por lo menos una creencia mínima en el poder de las instituciones de control, creencia que luego será refutada al preguntar por los mecanismos para acceder a estas instituciones o la efectividad de la norma y su capacidad para transformar una realidad. Tal y como se infiere de la siguiente declaración de un líder encuestado:

Mire, El Bagre es uno de los municipios más violentos de Antioquia en un pueblo como este que tiene 45.000 habitantes donde en un día se matan cuatro o cinco personas. Es violento, sumamente violento y aquí hay zonas donde si a usted no lo conocen no puede ir, y si usted quiere vaya a caminar por las colinas. Ahora meses mataron un profesor el año pasado; supuestamente, hizo una llamada a la policía y le cogieron otro teléfono y el área, y le quitaron el hijo de los brazos y le pegaron un tiro. Entonces la gente tiene miedo, usted sabe que al miedo no le pusieron pantalones. Los entes de control para mí no operan.

Se verifica la dualidad en la localidad estudiada, con las respuestas a las preguntas 
asociadas a la democracia como sistema. El $81,3 \%$ de la muestra precisa que prefiere la democracia frente a cualquier otra forma de gobierno. Pero al explorar las formas de participación que posibilita la democracia, esta afirmación se diluye paulatinamente: cuando se pregunta si la democracia es un sistema de gobierno que garantiza la participación de todos en los asuntos políticos, solo el 34,7 \% está totalmente de acuerdo.

A pesar de esto, el 47,7 \% de los encuestados asocia la democracia con el gobierno del pueblo. El 51,3 \% considera que la democracia garantiza al individuo sus derechos civiles, políticos, sociales, económicos y culturales. En consonancia con ello, el 46,7 \% de la muestra seleccionada considera que la democracia es una forma de gobierno donde el pueblo es quien ejerce el poder político y donde sus líderes son escogidos en elecciones libres.

De igual forma, los habitantes de El Bagre consideran que la democracia es funcional, ya que el $48 \%$ precisa que esta es el resultado de acuerdos y compromisos entre el ciudadano y el gobernante, para dar soluciones legítimas y pacíficas a las problemáticas de la sociedad. Así mismo, se cree en el papel deliberativo y autónomo que propicia la democracia, cuando el 49,3\% afirma que la democracia confiere autonomía y deliberación a los ciudadanos. Hasta aquí respuestas ideales para una abstracción ideal, que es como termina siendo percibida la democracia y sus mecanismos participativos.
La dualidad nacional-local se manifiesta con fuerza, cuando el 32 \% afirma que en Colombia y en sus entes territoriales la democracia es más representativa que participativa. Esto acompañado del 34 \% que evidencia un mediano interés en los temas políticos. El $31 \%$ habla medianamente de política y el 79,3 \% afirma taxativamente que nunca ha trabajado para un partido o movimiento político y que escucha a los políticos medianamente (33\%). Pero lo que preocupa de la muestra es que el $44 \%$ de las respuestas afirmaron nunca tratar de convencer a alguien de sus ideas políticas, así como el 79,3\% explica que nunca ha tratado de ejercer liderazgo político frente a otras personas, lo que evidencia pasividad y cansancio en el sistema democrático, el cual se defiende con fuerza en las percepciones anteriores. Con respecto a esto, se nota el agotamiento de los líderes políticos para movilizar la acción colectiva. A este respecto, un entrevistado precisó lo siguiente:

Sí, el reto más importante de esto es la falta de conciencia que tiene el pueblo de que su gobernante tiene un deber moral y ético de administrar bien los recursos, de que los recursos no son regalados ni son de los políticos, que los recursos son del pueblo y se deben aplicar en las obras de mayor prioridad que amerita la población. Entonces, el gran reto que tenemos nosotros, o que tengo yo, es despertar conciencia en toda la población para que sean objetivos en evaluar el alcalde y que no dejen solas a las personas que de alguna manera 
están haciendo esta labor, porque el gran beneficiado es el pueblo y esta conciencia la creamos compartiendo la información, la información de lo que realmente están haciendo los gobernantes. La invitación o reto que tenemos nosotros básicamente es crear la conciencia a través del compartimiento de la información pública que existe.

El orden en el cual los encuestados afirman defender los derechos varía en la medida en que se profundiza el análisis. La defensa de los derechos democráticos ocupa el quinto puesto con un $33,7 \%$. La propiedad de la tierra ocupa el cuarto puesto con un 40,3\%. El tercer puesto, con el $32,7 \%$, es ocupado por el derecho a un control efectivo de la explotación de los recursos naturales, en especial al oro. El segundo puesto es ocupado por el derecho a la lucha por las reivindicaciones de salario y mejores condiciones laborales $(38,7 \%)$. El primer puesto lo obtiene el derecho a la salud y a la educación que ocupa el $58,3 \%$ (todos son los picos más altos de una serie de preguntas diversas). Entre los datos más altos procesados, los derechos democráticos están de último.

Frente a la pregunta: ¿Cómo diría usted que es la democracia en el municipio de El Bagre?. La respuesta ubica dos dimensiones: el $44,7 \%$ considera que es una democracia con pequeños problemas y el $42,3 \%$ que es una democracia con grandes problemas, pero al sumar los resultados inferimos que es una democracia con problemas (91\%). La opinión pública medida cree que el principal problema de El Bagre es la delincuencia con un $32 \%$, la corrupción con un $28 \%$, el desempleo con un $22 \%$ y la pobreza con un $15 \%$.

Cuando se pregunta si se cree en el progreso de El Bagre, el 67 \% señala que sí y el $27 \%$ afirma lo contrario, considera que el progreso se encuentra estancado. La idea de progreso, al igual que la percepción de democracia, se mira como una gran abstracción, pero también se cuestiona en los líderes la inacción de los políticos y de los gobernantes. En palabras de un entrevistado:

El municipio de El Bagre es uno de los más jóvenes que tiene el departamento, pero que por aquella bendición o maldición, como también lo han Ilamado, de tener oro, regalías y demás, debería de estar inclusive mejor en muchas situaciones de tipo social; pero cuando yo hablo de la maldición hablo de aquellas bonanzas en las que muchas familias Ilegaron detrás del preciado material y se dieron situaciones, ya sea por violencia o por otros índoles. Pero también juega un papel importante la cultura minera, que vive del día a día, y no piensan en el mañana. Es así como fueron conformando barrios de manera anormal, eso hizo un cordón de pobreza muy alto que todavía lo tenemos y que hay que superarlo; que yo puedo hablar de lo que estoy haciendo en este momento donde estamos haciendo esfuerzos importantísimos en el tema de calidad de vida, de vivienda, acueducto, formalización de los 
terrenos y los predios. Aquí en El Bagre casi nadie tiene escrituras, hoy estamos haciendo un ejercicio para entregar más de 5.000 escrituras y decirle a la gente venga sea dueño, venga tribute, venga haga reconocimiento para poder aplicar a programas de vivienda y mejoramientos. Tenemos de los municipios del Bajo Cauca el más alto índice de régimen subsidiado en salud, nosotros subsidiamos aquí a más del $70 \%$ de la población con un agravante: nosotros somos 48.500 personas para el DANE, 65.000 para el SISBEN, pero atendemos más de 100.000 personas porque al ser El Bagre un centro poblado, por su aeropuerto y sus condiciones, nos llega gente del sur de Bolívar, de Nechí, de Zaragoza, de Segovia. Y somos nosotros el referente para la atención de toda esta gente, entonces yo considero que en el tema de la percepción de la corrupción hemos ganado un gran espacio por ser claros y por decirle a la gente qué estamos haciendo, qué llega y cómo se invierte. Acabamos de pasar a cuarta categoría es un esfuerzo importantísimo en un año y eso se ve reflejado en el compromiso del buen uso del recurso y en el compromiso del excedente entre el recurso que antes se recogía del orden municipal y con el esfuerzo que la gente ha hecho por pagarnos, pero porque creen y confían en lo que estamos haciendo.

Cuando se pregunta por la fuerza de la acción colectiva, las siguientes son las respuestas que evidencian una disposición total a la participación en temas que afectan a la comunidad y en la defensa de los derechos anteriores:

- ¿Saldría usted a marchar y a protestar por defender los derechos democráticos? El 30,7 \% respondió algunas veces.

- ¿Saldría usted a marchar y a protestar por defender la propiedad de la tierra? El $30,75 \%$ respondió siempre.

- ¿Saldría usted a marchar por un control efectivo a los recursos naturales en especial al oro? El $32 \%$ respondió siempre.

- ¿Saldría usted a marchar y a protestar por un aumento real del salario y luchar por unas mejores condiciones de vida? El $53 \%$ respondió siempre.

- ¿Saldría usted a marchar y a protestar por la mejora de la salud y la educación? El $54 \%$ respondió siempre.

Nótese que todos los picos están en el nivel de siempre o casi siempre. Pero al llegar a la parte relacionada con mecanismos e instrumentos de participación ciudadana o de acción colectiva y de participación efectiva y real, las respuestas evidencian la realidad: un desconocimiento casi absoluto de las diferentes alternativas dadas por el marco normativo y la Constitución Política de 1991.

Nuevamente la intención y la acción se disocian en el binomio de preguntas sobre participación en veedurías ciudadanas. El 50,3\% de la muestra respondió estar de acuerdo en formar parte de una veeduría, ya que así vigilaría socialmente la gestión de los recursos públicos, el 45,3 \% señaló estar de acuerdo 
en participar en una veeduría para ejercer control sobre la prestación de los servicios públicos. En ese mismo contexto, se hace una alabanza de las personas que denuncian; el $53 \%$ de la muestra señala que los ciudadanos que denuncian son honestos y dignos de imitar.

Pero al llegar a los niveles de participación y al conocimiento de las leyes y mecanismos, así como al intento de medir las actitudes frente a las veedurías, las respuestas están distantes de la fe en la democracia y la percepción mediana en sus instituciones. Frente a la pregunta: ¿A cuáles de las siguientes organizaciones de participación social, comunitaria y/o política ha pertenecido o pertenece? La soledad de la participación se hace evidente: los picos más altos están en la no pertenencia a ningún tipo de organización.

El desconocimiento de los instrumentos o herramientas para solicitar información pertinente a las organizaciones públicas ocupa un porcentaje elevado, ya que la población afirma no conocer ningún modelo de participación. Esta apatía se ve reflejada en las entrevistas, particularmente en lo expresado por este ciudadano:

La veeduría ciudadana está frente a un poder económico, frente a un poder político. Los gobernantes le perdieron el temor a la justicia, se pisotean las leyes y muy poco les importan que hayan veedurías o no porque hay inmensos intereses donde existe una pared que no nos deja ver. El problema consiste en que parece que le perdieron el respeto a las autoridades, parece que no se respeta la ley, parece que todo es un juego. Uno ve que los gobernantes juran y al ratico violan la ley. Si las autoridades de control hicieran unos avalúos serios frente a las administraciones, seguro que encontrarían muchos errores como los que encontró la Corte Constitucional cuando revisó la segunda campaña de la reelección para la Presidencia de la República, pero nos sentimos que estamos solos, que no existen los mecanismos de las autoridades de control para controlar tanta corrupción.

Esto puede ser probablemente explicado por el desconocimiento de los mecanismos, lo cual enfrenta la férrea y dogmática defensa de la democracia expresada en respuestas anteriores. El desconocimiento de los mecanismos de participación es abrumador en la muestra seleccionada. Lo que impacta a simple vista de las cifras encontradas es que luego el $66 \%$ de los encuestados concuerden con la idea de que la normatividad y el exceso de reglamentación son los factores que impiden y obstaculizan la participación ciudadana y el control social. Este tema es absolutamente contradictor con las respuestas anteriores de intencionalidad en la participación, dado que se desconocen los aspectos normativos de la ley. Un entrevistado afirma al respecto lo siguiente:

Se oye mal, pero la verdad hay que decirla y es que siempre hemos sentido un aisla- 
miento, un rechazo por parte de la administración pública desde que se fundó la veeduría ciudadana para los recursos de impuestos y regalías oro. Acá ha sido la preocupación de nosotros como veedores que tengamos al menos en nuestra población lo básico, lo elemental, de acuerdo a esos ingresos que dejan esos recursos. Sin embargo, se hace todo lo contrario. Acá ha habido recursos para nosotros tener agua potable apta para el consumo humano las veinticuatro horas, no la tenemos. Tenemos un hospital que fue creado para 12.000 habitantes y somos más de 65.000 habitantes, y todavía los recursos de impuestos y regalías del oro no se ven reflejados en la atención en salud, en plan maestro en agua potable, alcantarillado, saneamiento básico. No entiendo cómo un presupuesto de una población de 65 - 60.000 habitantes, que sobrepasa los 26.000 millones de pesos, no tenga estos servicios básicos. Entonces sí hay plata, sí hay plata para hacer burocracia, sí hay plata para hacer politiquería. Ahí es donde no entiendo.

Podríamos entender la dinámica de precariedad democrática y ciudadanía dual que se presenta en El Bagre indagando por los niveles económicos de vida. Las respuestas dan luces de cómo, de una forma u otra, lo económico incide en la percepción de la democracia, es decir, las expectativas de la democracia chocan abruptamente contra el muro de la pobreza en los ingresos económicos y la estabilidad financiera. Esto hace que la variable de ingresos económicos sea directamente proporcional a la variable de democracia efectiva y real, al menos en la localidad estudiada.

A este respecto, Marta Lagos señalaba taxativamente cómo existe una relación directa entre economía y "buena democracia", así como un desarrollo positivo de los niveles de acceso del ciudadano al Estado. De igual manera, los niveles de pobreza y atraso económico inciden negativamente en el funcionamiento institucional democrático potenciando la desconfianza interpersonal e institucional, lo que a su vez, según Domínguez y Shifter (2005), crea "un orden pluralista en el cual los ciudadanos están solos ante las autoridades y un orden político constituido por individualidades, en el cual las redes de asociación y los grupos de interés capaces de influir en las autoridades no han sido un instrumento de progreso y desarrollo" (p. 161). Los encuestados consideran que la desigualdad económica que impera en El Bagre, así como la pobreza y el desempleo, impiden y obstaculizan la participación ciudadana y el control social; en esto están de acuerdo el $41,7 \%$ de la muestra y totalmente de acuerdo el $24,3 \%$. La ausencia de credibilidad en las instituciones y en las entidades de control como grandes obstáculos a la participación ciudadana y el control social a la gestión pública, ocupa un $45 \%$ en el ítem de acuerdo y un $29,7 \%$ de totalmente de acuerdo.

Al revisar las condiciones económicas de la población, se pueden verificar los niveles de 
pobreza y de necesidades básicas insatisfechas, que se tornan un elemento reiterado en casi todas las entrevistas realizadas. Tal y como lo señala un entrevistado:

La corrupción existe en todo el país y este Bagre, que yo quiero mucho, hace parte de este país. Yo no me imagino un municipio que tenga 33.000 millones de presupuesto, donde hay 45.000 habitantes y haya gente con tantas necesidades básicas insatisfechas. Uno ve en el centro calles pavimentadas, pero usted se va cinco minutos en moto y están las calles rotas, sin alcantarillado, las aguas residuales y aguas malolientes corriendo por las calles, animales sueltos; es un caos. Entonces yo me pregunto: ¿dónde está la plata que pagan las empresas mineras? Porque ellos explotan oro y saben los desembolsos que hacen o sabían por regalías y por impuestos. Ahora supongo que las regalías irán para otro lado, pero llegan los impuestos, ¿dónde está realmente el presupuesto del municipio?, ¿porque en la administración pasada, por ejemplo, se pavimentaron calles? Pero esas calles son del programa Antioquia pavimentada, entonces ¿donde está la plata? Si mal no recuerdo, aquí en tanto tiempo con un solo alcalde se han tomado acciones colectivas, los demás se han enriquecido y han pasado como Pedro por su casa, sin gloria y con mucha pena.

Al caracterizar las condiciones económicas de los habitantes de El Bagre, la muestra encuestada precisa que es difícil el tema de la alimentación, dado que los ingresos posibilitan una alimentación adecuada, algunas veces un $32 \%$, casi siempre un 27,67 \% y siempre un $23,67 \%$. El tema de la educación implica que el salario algunas veces posibilita cumplir con los compromisos económicos que implica el proceso educativo (43\%); alcanza algunas veces para los gastos de vivienda (39\%) y algunas veces les permiten cubrir los servicios públicos (38,3\%), nunca les posibilita ahorrar (64,3\%). Pero la respuesta absoluta es cuando afirman que los ingresos por salario, nunca permiten recreación y deportes (43\%).

Esta marginalidad rural se aprecia en la mirada de los líderes comunitarios que señalan la precariedad en todos los niveles de lo público; de igual forma, permite entender el enfrentamiento entre la lógica privada y la lógica de lo público:

Veo que en nuestro municipio, que a pesar de ser un municipio que tiene grandes recursos, que tienen un gran presupuesto, que supera los cien mil millones de pesos en los cuatro años, es un municipio que no aplica bien esos recursos y cada día las necesidades siguen iguales. Vemos que es evaluado mal a nivel de desempeño municipal por planeación nacional, que en niveles de vida queda mal parado en las encuestas que hace el departamento de Antioquia, la encuesta anual de calidad de vida. Vemos que en servicios públicos hay muchas falencias, no hay agua potable, no hay continuidad, no hay gran cobertura; 
vemos que no tiene parques ambientales, no tiene mataderos, no tiene plazas públicas. Entonces, viendo este gran atraso que tiene el municipio de El Bagre y viendo los grandes recursos que tiene, me veo en la obligación como ciudadano de cuestionar, preguntar, criticar objetivamente: ¿por qué estas cosas no se hacen?, ¿por qué otros políticos no aplican y ejecutan bien los recursos?

El análisis cuantitativo y cualitativo explicitado en párrafos anteriores, permite identificar un panorama donde el nivel de ingresos de la municipalidad da cuenta del precario nivel de inversión para la solución de las necesidades básicas de la población, a lo que se le deben sumar otros factores más acuciantes, tales como el dominio del territorio por actores ilegales del conflicto, las violencias propiciadas por el control de la propiedad de la tierra y la degradación de los suelos y acuíferos por la minería (legal e ilegal).

El nivel político analizado se caracteriza por presentar altos niveles de captura del Estado desde lo local (dualidad de la sociedad colombiana), por parte de los grupos de poder (narcotráfico, paramilitares y, en menor proporción, grupos guerrilleros), los cuales atentan directamente contra el desarrollo de proyectos democráticos, deteriorando con el uso de la fuerza el derecho fundamental a la participación; o, de manera más sutil y menos violenta, incidiendo con su poder económico en los estamentos de autoridades locales (civiles y militares). Este fenómeno se orienta en la direccionalidad señalada por Hellman y Kaufmann (2001):

En las economías en transición, la corrupción ha forjado una nueva imagen: la de los llamados oligarcas que manipulan la formulación de las políticas e incluso configuran las nuevas reglas del juego para su propio beneficio. Éste es el comportamiento que denominamos captura del Estado. Si bien esta forma de corrupción a gran escala se reconoce como el problema más pernicioso y difícil de detectar en la economía política de las reformas institucionales y económicas, se han hecho pocos esfuerzos sistemáticos para distinguir sus causas y consecuencias de las de otras formas de corrupción. Tampoco ha habido intentos de medir esta clase específica de corrupción ni de comparar su incidencia en los distintos países. Por captura del Estado entendemos los intentos de las empresas para influir en la formulación de las leyes, las políticas y la reglamentación del Estado a cambio de pagos ilícitos -con carácter privado-a los funcionarios públicos (p. 31).

En cuanto a la ausencia de un rol significativo de la sociedad civil, la participación ciudadana y el buen gobierno han sido golpeados por actores estatales, paraestatales y grupos subversivos, pues su accionar se vuelve sospechoso ante los ojos de dichos actores. Es así como se presenta en los líderes una mezcla entre incredulidad frente a las políticas del Estado y su promocionada lucha contra 
la corrupción, y el temor frente a la reacción de los actores violentos con respecto a la participación, especialmente al control ciudadano de la gestión pública. Uno de los entrevistados planteó lo siguiente:

Estas personalidades con un trabajo muy altruista y casi que de superhéroe, porque este no es un papel o un rol grato, este es un rol ingrato, porque a pesar de uno luchar por el pueblo lo que uno obtiene son en su mayoría enemigos y señalamiento. Vea, las herramientas en el papel son como la Ley 100, como dice el dicho popular, "el papel aguanta todo". La Ley 100 es muy linda en el papel, el derecho de petición, la tutela es muy, muy bonita en la literatura, pero al aplicarla, cuando uno encuentra barreras como la del juez, el personero, el que le brinda, el humilde archivador o el humilde secretario de despacho que le puede brindar una información veraz eficaz contundente, cuando uno ve que todo eso es truncado, que ponen traba, que hay que pagar las fotocopias, que las copias que le entregan a uno es ilegible, que cuando se usan presupuesto y cuando se usa doble contabilidad, ahí es donde uno ve que no hay moralidad, no hay principio de transparencia en ninguno de los actores que se está vigilando y los mecanismos fallan.

En este orden de ideas, es pertinente mencionar el tema de la rendición de cuentas de los agentes del Estado, la cual por lo general está limitada en estricto modo a la tarea ru- tinaria de presentar informes de gestión, la mayoría de ellos "maquillados", sin la posibilidad de acceso a la información por parte de la ciudadanía, que pueda corroborar lo dicho por los administradores públicos.

Esto hace que la democracia participativa de la sociedad bagreña esté ausente de la vida política, como lo están las soluciones a los grandes problemas sociales. Como ya lo había planteado Mina Paz, la legislación sobre participación ciudadana en Colombia deja demasiados vacíos que al final terminan convirtiéndose en un freno a sus propias ambiciones:

Ese vacío ha sido aprovechado para recrudecer políticas perversas que han reducido sus grandes posibilidades a simples espejismos jurídicos de buenas intenciones. En síntesis, los mecanismos consignados en las distintas leyes tienen que ver con las posibilidades que tienen los ciudadanos de informarse sobre la acción y actuación democrática, pueden ser objeto de manipulación por parte del gobernante de turno. El país está aún inmerso en una encrucijada y enfrentar males como la guerrilla, el paramilitarismo, la corrupción, la delincuencia común, la inoperancia del aparato de justicia, el atraso tecnológico, la pobreza, el desempleo, los pésimos niveles de cobertura en la educación pública, la escasa producción agroindustrial; requiere de grandes compromisos políticos y económicos con los sectores populares. No es suficiente realizar veedurías, fisca- 
lizar o aplicar algunos de los mecanismos consagrados en la ley $(2005$, p. 2).

Con esto, se logra la clarificación de un concepto fundamental para entender el accionar del Estado; una cosa son los problemas sociales y otra muy diferente, las situaciones socialmente problemáticas que ayudan a una aproximación sobre la comprensión de la relación que ha tenido el Estado con la región. Cuando se habla de El Bagre, generalmente se asocia a problemas de orden público (minería ilegal, narcotráfico y conflicto armado), mientras que la mayor intervención del Estado se presenta con la implementación de políticas públicas, que tienden a asegurar el bienestar de los inversionistas nacionales y extranjeros que explotan la región. Dichos actores económicos (nuevas élites) representan los grupos de presión más poderosos de la región y definitivamente es hacia ellos y sus capitales, donde se dirige toda la atención del Estado para su protección.

Las demás políticas públicas generadas por el Estado, como la disminución de la pobreza, se limitan a un papel asistencialista y generalmente terminan siendo cooptadas por los poderes políticos locales, para afianzar su poder clientelar en las poblaciones. Este poder se preserva en las relaciones económicas en el binomio de un ciudadano-cliente que, de forma alterlegal, se beneficia de las redes cooptadas por los grupos in.

Nos encontramos, así, frente a una nueva distorsión de la ciudadanía, que exige dere- chos, defiende la democracia, pero se aparta de las instituciones, no participa y desconoce los marcos normativos en los cuales puede hacer valer los derechos, lo cual nos lleva a una pseudo-democracia y a una norma vacía que carece de fuerza fáctica. Este círculo anómico reproduce niveles de ciudadanía cínica, es decir, ciudadanos que nominalmente exaltan los derechos democráticos, pero con el mínimo posible de las obligaciones que estos presuponen.

Visto así, se cae en círculos cerrados de problemas que restringen el sistema. Dado que los ciudadanos no confían en las instituciones y estas, cuando son enfrentadas con sus fallas, devuelven la responsabilidad al ciudadano, le señalan que las fallas y la corrupción se dan precisamente en el marco de su inacción ciudadana y de su falta de injerencia en los asuntos políticos. Tal y como lo aseguró uno de los alcaldes entrevistados:

Hemos hecho nosotros énfasis en que la participación ciudadana y la veeduría no se pueden convertir en "persecuraduria", en perseguir al político de turno, en que el mejor ejercicio que puede hacer un veedor, aunque él tiene la potestad de hacerlo antes durante y después es hacerlo en el ejercicio. Los alcaldes nos mantenemos demasiado ocupados y muchas veces en los procesos licitatorios suceden situaciones por desconocimiento en la ejecución, pero cuando una veeduría llama la atención al contratista y le informa al alcalde a tiempo -sobre todo, no esperan que la 
obra sea un fracaso, para luego ponerlo en aprietos-, creo que es el mejor ejercicio que se puede hacer, para así contrarrestar de manera franca y directa la corrupción y lograr vincular a la comunidad. Cuando mando a hacer una obra, y puedo decirlo con toda la alegría que me da, de las 84 veredas que tiene El Bagre, he ido a 60 y cada que hay una obra, yo voy detrás de la obra y le he dicho a las comunidades, a los presidentes, a las veedurías, si las obras quedan mal es porque es culpa de ustedes, porque son pasivos, porque no actúan a tiempo, que al contratista le pidan en el contrato y verifiquen si la alcaldía mando hacer allá una vía; sencillo, pidan el contrato.

Nótese que se acusa a la veeduría de "persecuraduría", y también al mismo tiempo, de inacción y de ausencia de control. Son las dos dimensiones en las que se mueven los actores institucionales cuando se trata de señalar las falencias y la efectividad organizacional, así como el ingreso a la corrupción. Pareciese, en este marco de análisis, llegar a una especie de dialéctica negativa, donde no hay superación de la contradicción, es decir, no existe la posibilidad de la trascendencia de una situación que, basados en la desesperanza que produce el modelo, no mejora.

Para finalizar, es pertinente resaltar como paulatinamente existen otros procesos de dominación hegemónica, que en El Bagre son evidentes, es decir, la existencia de instituciones que de una manera muy particular han venido colonizando el ámbito de lo público, pero con una visión de lo privado y privativo. Existe una tendencia fuerte donde los espacios de participación se llenan con una participación seleccionada, elitizada y llena de expertos; este proceso de expresión local es alimentado por una tendencia de corte global: la democracia experimentalista que deviene en democracia instrumentalizada (Latorre, 2015).

\section{CONCLUSIONES}

Este artículo de resultado de investigación inició señalando el caudal desbocado de los ríos propios de la acción colectiva sin sentido y amorfa. Es pertinente terminarlo haciendo un ejercicio de memoria, particularmente, de una memoria colectiva que resignifique el rol de los ciudadanos que lograron entender el beneficio de la participación y el ejercicio de los derechos y que, a pesar de tener todo en contra, tuvieron el coraje de defender lo público de los cercos y saqueos de lo privado y privativo, así como de los órdenes alterlegales, que se nutren de las debilidades del Estado colombiano y de su dualidad.

En este orden de ideas, se hace necesario revisitar el caso de la muerte del médico Raúl Gómez Rendón, asesinado por los paramilitares ante su negativa de entregar el presupuesto de la salud del hospital de El Bagre. A continuación me permito citar unos fragmentos de una semblanza realizada por Ildefonso Castilla Amell (2014), miembro del Comité de Veeduría Ciudadana para los Re- 
cursos del Impuesto y Regalías Oro del Municipio de El Bagre y quien para la época del asesinato del médico Gómez se desempeñaba como personero de dicha municipalidad. Estos fragmentos se transcriben con autorización del autor.

Recordar cómo fue truncada la vida de este líder es evocar también los momentos de una tragedia estremecedora de la sociedad bagreña, pues nos llevó a experimentar sentimientos de horror y pánico colectivo por el asesinato del médico, y de angustiosa frustración, en tanto supimos de la autoría de su muerte violenta y la trama urdida por los responsables: Al médico RAÚL GÓMEZ lo asesinaron vilmente los paramilitares, para tomarse el Hospital, capturar su presupuesto y así fomentar la corrupción poniéndola al servicio de sus intereses económicos. Previamente hicieron que los concejales, ya convertidos en borregos de la causa paramilitar, lo citaran al Recinto el 31 de mayo de 2002 a enfrentar un debate sobre el manejo de la E.S.E. Hospital Nuestra Señora del Carmen en el cual fungía como Gerente. El referido debate fue tan calculado por los citantes como nefasto para la suerte del gerente, pues allí este se vio obligado a revelar lo ocurrido con los dineros producto de un empréstito obtenido por la administración anterior para cancelar deudas del Hospital, recurso este desviado hacia otras manos a través de quienes regentaban la dirección técnica, administrativa y financiera de la E.S.E., siendo beneficiarios del latrocinio los mismos mercenarios de la organización armada.

Los criminales temieron que el Gerente aprovechara la nueva reunión pública para denunciar ante el Concejo las pretensiones extorsivas de éstos contra él, porque ya le habían fijado "cuotas de dinero" del presupuesto del Hospital y plazos para "pagarlas", pero el Médico se resistía a satisfacer tales exigencias por la decisión estoica de proteger los recursos públicos, aun a expensas del riesgo inmerso en su actitud, pues quienes lo conocimos sabíamos que él actuaba tal como pensaba. Por eso el designio criminal no podía darse treguas, pues con la muerte de este líder se aniquilaría toda posibilidad de control social, y quizá fiscal, sobre los actos de la Administración Pública en todos los niveles del ámbito municipal. Para los homicidas no era conveniente esperar hasta el otro día, porque era necesario evitar la continuación del debate. Esto al parecer aceleró la decisión de alias "JJ" y de alias "Cuéllar" de pedir a alias "Macaco" la orden para ejecutar ese mismo día al médico RAÚL GÓMEZ, y en cuestión de horas movilizaron desde Cuturú (corregimiento de Caucasia) al sicario mejor calificado como efectivo de la organización, según lo pregonaban sus propios cabecillas. El sicario lo asesinó propinándole dos impactos de bala cuando, a las seis de la tarde, el médico se encontraba en un establecimiento público distante sólo dos cuadras del Cuartel de la Policía Nacional. 
"Lo matamos porque entrenaba a los guerrilleros..." (esto mismo repitió "Macaco" en el más reciente de los juicios adelantados en su contra y en calidad de extraditado); "Io matamos porque le suministraba medicamentos a la guerrilla"; "lo matamos porque no nos quería colaborar". En fin, de todos estos cargos tan cínicamente inventados por ellos, ya la víctima no se podía defender y sus dolientes tampoco podían hacerlo, en tanto no solo estaban sus ánimos desvanecidos por el dolor, sino también controlados por las acciones intimidantes de los escuadrones de la muerte, quienes en actitud triunfalista pregonaban haberlo ultimado en nombre de la contrainsurgencia como si fuera esa la verdadera causa por ellos defendida.

Nosotros en cambio, sin poder evadirnos y a pesar de nuestra actitud vigilante, seguimos asistiendo al espectáculo ofrecido todos los días por los actores de la corrupción en la Administración del Municipio, viendo cómo avanza airosa devorando los recursos del presupuesto, a expensas de lo cual, cada vez más los protagonistas se arraigan en el poder público y se han hecho amos de la voluntad política del pueblo elector para perpetuarse en los cargos públicos hasta satisfacer totalmente sus intereses personales, amparados por la mirada indiferente del pueblo mayoritario, porque no los eligió y la actitud resignada de las minorías de electores, sin ninguna capacidad de reacción, pues votaron alienados a cambio de un favor, ven- dieron el voto, participan del festín de la contratación, o están recibiendo migajas del presupuesto oficial.

Estos fragmentos de la semblanza de un ciudadano y líder con coraje son el pretexto necesario para concluir y señalar los hallazgos de esta investigación, los cuales pueden ser contextualizados de la siguiente forma:

Existe un desfase entre el universo ideal, arquetípico de lo que es la democracia como sistema, que no es coherente con una práctica cotidiana que esté en concordancia con lo que implica la misma democracia. Se alaba la democracia y sus mecanismos de participación ciudadana, pero se asume una ciudadanía cínica que reniega de la misma, reclama los derechos pero no cumple con los deberes que implican el empoderamiento ciudadano y la defensa colectiva del bien público.

La conversión paulatina del discurso de cliente ciudadano, le da mayor fuerza al carácter económico y privativo propio de las fuerzas alienantes del mercado y del consumo, impregnando las relaciones entre el Estado y el cliente de las fuerzas racionalizantes y excluyentes del ámbito neoliberal. El concepto de lo público se subsume en la lógica de lo privado y se coloca en la esfera de dominio de grupos de poder elitizados que son los que pueden acceder a las ventajas de la participación.

La colonización del lenguaje por parte de las técnicas neoliberales hacen que lo interpela- 
tivo, es decir, lo argumental, clave dentro de la democracia experimentalista, se diluya en la fuerza de los stakeholders, quienes cooptan el sistema y se adueñan de las gramáticas jurídicas, haciendo que lo público se difumine en las luchas altamente conflictivas entre lo público y lo privado.

La conversión del ciudadano en cliente implica una sutil y seductora desarticulación de la acción colectiva y del empoderamiento ciudadano, generando nuevas exclusiones, las cuales hacen que solo cierto grupo de "expertos" puedan manejar el acceso al Estado. De ahí la preservación de la dualidad de la sociedad colombiana, que hace que exista un país legal en las principales ciudades y un país alterlegal en la periferia.

Los datos esgrimidos en este trabajo permiten afianzar la idea de dualidad, de cooptación de lo público por parte de lo privado y de una ciudadanía cínica que se niega a asumir su papel protagónico en el proceso de materialización de la norma social. Para que una norma pueda ser real necesita una sociedad que lo posibilite, de ahí que la noción de los derechos sobre participación, como mascarada neoliberal, adquiere validez a la luz de la debilidad de la norma, de una norma que existe en el papel y en ciertos lugares del país, pero que debe transitar los peligros de la periferia para poder materializarse.

Finalmente, se hace un llamado a la necesidad de explorar la construcción de ciudadanías empoderadas que rescaten el coraje, es decir, el valor para enfrentar la defensa de lo público en contra de todos los intereses que lo amenazan. Ya lo había señalado el entonces senador J. F. Kennedy, cuando hacía un llamado a la defensa de lo público y a cerrar filas en torno a la acción ciudadana, que alimentada de una fuerza axiológica podía transformar realidades:

Los problemas del coraje y la conciencia no solamente conciernen a cada mandatario de nuestro país, por más humilde o poderoso que sea o frente a quien es responsable... Conciernen igualmente a cada elector e incluso a aquellos que no votan, que no tienen interés en el gobierno y que hasta desprecian al político y su profesión. El problema del coraje y de la conciencia concierne también a todo aquel que una vez se quejó de la corrupción de aquellos que ocupan altos cargos, así como a todo aquel que exige que el diputado elegido por el cumpla con sus deseos. Porque en la democracia cada ciudadano, cualquiera sea su interés en la política, es un "mandatario", cada uno de nosotros de alguna manera es responsable de algo, y la forma del gobierno que tenemos depende finalmente de cómo cumplimos nuestra responsabilidad... Cualquiera que sea la arena de vida para encontrar el desafío del coraje, cualquiera que sea el sacrificio para nuestra conciencia -la pérdida de amigos, de fortuna, de serenidad y aun el aprecio del prójimo-, cada uno de nosotros tiene que decidir por si mismo que camino seguir. A través de las historias 
de coraje del pasado podemos aclarar su calidad, a través de ellas podemos aprender y podemos recibir esperanza e intuición -pero no el coraje mismo-. Este cada uno tiene que buscarlo en su propia alma (Kennedy, 1956, pp. 256-257).

Los quijotes colombianos como Apolicenia y Raúl abundan en las historias perdidas de una Colombia que defiende lo público. Estos quijotes murieron resguardando lo que para muchos era una locura, su enfrentamiento contra los gigantes de lo alterlegal evidencia que detrás de estas historias están las vivencias de personas anónimas con el coraje suficiente para luchar por lo que todos consideraban perdido. Vincular los procesos de reconstrucción de la memoria del coraje es una tarea pendiente, si queremos transitar la senda del postconflicto.

\section{REFERENCIAS}

Acemoglu, D. \& Robinson, J. (2012). Por qué fracasan los países. Los orígenes del poder, la prosperidad y la pobreza. Bogotá: Deusto.

Agencia de Prensa IPC (2011). Bajo Cauca antioqueño: radiografía de una protesta poco comprendida. Campesinos de la región reclaman mayor apoyo y presencia del Estado, sábado 12 de marzo de 2011. En: http://prensarural.org/spip/spip.php?article5463

Angulo Mira, G. (1982). Monografía de El Bagre Libros. Medellín: Bedout.
Arendt, H. (1993). La condición humana. Barcelona: Gedisa.

Arias, B. \& Vélez, R. (2010). El control social como elemento fundamental en el ejercicio de la democracia participativa. Revista Lecciones de gobierno, I(1). Medellín, Colombia.

Aristizábal, I. y otros (2004). Sistematización de experiencias de veedurías ciudadanas y control social en la administración. Bogotá: Universidad de la Salle.

Ayala, C. (2001). Leer la política. Revista Historia Crítica, (20). Bogotá: Universidad de los Andes.

Bauman, Z. (2007). Vida de consumo. Madrid: Fondo de Cultura Económica.

Bauman, Z. (2010). Modernidad líquida. México: Fondo de Cultura Económica.

Bautista, J. F. (2011). El control social y su relación con los procesos de formación de capital social y movilidad social: algunos indicios a partir de experiencias en Bogotá y Cundinamarca. Bogotá: Ediciones Fundación Universidad.

Benjamín, W. (2010). Tesis sobre la historia y otros fragmentos. Bogotá: Desde Abajo.

Berquist, C. (1981). Café y conflicto en Colombia (1886-1910). Medellín: FAES.

Bobbio, N. (1989). El futuro de la democracia. México: Fondo de Cultura Económica. 
Bobbio, N. (1996). El filósofo y la política. México: Fondo de Cultura Económica.

Briones, G. (1996). La formulación de problemas en investigación social. Bogotá: Editorial Suramericana.

Busnell, D. (2014). Colombia, una Nación a pesar de sí misma. Bogotá: Planeta.

Caracol Radio, Con fondos de hospitales financiaban a paramilitares colombianos, marzo 5 de 2010. En: http://www.caracol. com.co/noticias/judiciales/recursos-de-loshospitales-públicos-sirvieron-para-financiarauc/20100305/nota/963485.aspx http:// www.lea.org.co/DesktopModules/Articulos/ DetallesArticulo.aspx?id=1595

Castells, M. (2009). Comunicación y poder. Madrid: Alianza Editorial.

Castilla Amell, I. (2014). Semblanza de un mártir: a propósito de la muerte del doctor Raúl Gómez. Texto inédito.

Chomsky, N. \& Herman, E. (1990). Los guardianes de la libertad. Barcelona: Editorial Crítica.

Colectivo de Abogados José Alvear Restrepo, Tutela en contra de "Macaco", www.colectivodeabogados.orgIMGdocTutela_Macaco03, 7 abril de abril 2008

Consejo de Estado (2013). Sala de lo Contencioso Administrativo. Sección Tercera.
Subsección B. Bogotá, D.C., 30 de octubre de 2013. Expediente 29735.

Contraloría General de la República. Guía Audite 3.0 Capítulo VIII. Criterios y Procedimientos, Auditorías Articuladas, 2.2.5.1.

Corporación Nuevo Arco Iris (2007). Parapolítica: la ruta de la expansión paramilitar y los acuerdos políticos. Bogotá: Intermedio Editores.

Cortés Rodas, F. (2010). El contrato social liberal: John Locke. Revista Co-herencia, 7(13), julio-diciembre. Medellín: Universidad EAFIT.

D’Adamo, O., García Beaudoux, V. \& Freidenberg, F. (2007). Medios de comunicación y opinión pública. Madrid: McGraw-Hill.

De Sousa Santos, B. (2004). Democratizar la democracia. México: Fondo de Cultura Económica.

De Sousa Santos, B. (2005). Reinventar la democracia: reinventar el Estado. Buenos Aires: CLACSO.

De Sousa Santos, B. \& Rodríguez Garavito, C. (eds.) (2007). El derecho y la globalización desde abajo. Hacia una legalidad cosmopolita. Barcelona: Anthropos Editorial.

Domínguez, J. \& Shifter, M. (2005). Construcción de gobernabilidad democrática en América Latina. México: Fondo de Cultura Económica. 
Dufour, G. (2007). Gobernabilidad y desarroIlo humano. En curso sobre gobernabilidad y construcción de escenarios prospectivos. Buenos Aires: Flacso.

Del Corral, G. (2003). Evaluación de la función y potencial de las fundaciones mineras y su interacción con las comunidades locales. Santiago de Chile: CEPAL, División de Recursos Naturales e Infraestructura.

Durkheim, É. (1998). Educación y pedagogía. Buenos Aires: Losada.

Durston, J. (2001). Capital social -parte del problema, parte de la solución-. Su papel en la persistencia y en la superación de la pobreza en América Latina y el Caribe. Santiago de Chile: CEPAL.

Echeverri, H. (2011). Propuesta de desarrollo para El Bagre, 2012-2015. "Diciendo y haciendo para que El Bagre siga creciendo".

Escobar, A. (1999). El final del salvaje. Bogotá: Cerec.

Espitia Zamora, J. E. (2013). Las regalías y los descuentos tributarios en la explotación de metales preciosos. Revista VOX POPULI, (12), 39-50, septiembre.

Evans, P. (2007). Instituciones y desarrollo en la era de la globalización neoliberal. Bogotá: Editorial ILSA.
Foreing Policy (2014). Recuperado en: http://www.fp-es.org/indice-de-estados-fallidos-2014

Gallup (2013). Barómetro global de felicidad y esperanza. Washington: Win Gallup.

Garay Salamanca, L. J. (2008). La captura y reconfiguración cooptada del Estado en Colombia. Bogotá: Transparencia por Colombia.

Garay Salamanca, L. J., Salcedo Albarán, E. (2012). Narcotráfico, corrupción y Estados. Cómo las redes ilícitas han reconfigurado las instituciones en Colombia, Guatemala y México. Bogotá: Debate.

García Villegas, M. (2010). Estado alterado. Clientelismo, mafias y debilidad institucional en Colombia. Bogotá: Centro de justicia.

Gargarella, R. (2011). El ideal de la democracia deliberativa en el análisis del sistema representativo. Algunas notas teóricas y una mirada sobre el caso de la Argentina. Tomado de http://74.125.155.132/sch olar?q=cache:piZTwRjLIMJ:scholar.google. com/\&hl=es\&as_sdt=0

Gobernación de Antioquia (2007). Antioquia en cifras, información subregional y municipal. Editorial Gobernación de Antioquia.

González, F. (1997). Para leer la política. Ensayos de historia política colombiana. Dos tomos. Bogotá: CINEP. 
González Ordovas, M. J. (2003). Ineficacia, anomia y fuentes del derecho. Madrid: Universidad Carlos III.

Gramsci, A. (1980). Los intelectuales y la organización de la cultura. Buenos Aires: Ed. Nueva Visión.

Greenspan, A. (2008). La era de las turbulencias: aventuras en el nuevo mundo. Barcelona: Ediciones B.

Guevara Salamanca, J. D. (2009). La democracia participativa como instrumento de dominación de la esfera pública. Una mirada crítica a la realidad política colombiana a partir de la Constitución de 1991. Tomado (17 de mayo de 2011) de http://repository.urosario. edu.co/bitstream/10336/1578/1/80871509. pdf

Guillén Martínez, F. (1996). El poder político en Colombia. Bogotá: Planeta Editores.

Gutiérrez, F. (2007). Participación ciudadana y pobreza en Colombia. Bogotá: DNP.

Habermas, J. (1994). Historia y crítica de la opinión pública. Barcelona: Ediciones G. Gilli.

Hellman, J., Jones, G. \& Kaufmann, D. (2001). Capture al Estado, capture el día. Estados Unidos de Norteamérica: Banco Mundial.

Jaeger, W. (1982). Alabanza de la Ley: los orígenes de la filosofía del derecho y los griegos. Centro de Estudios Políticos y Constitucionales.
Jager, W. (1995). Cristianismo primitivo y paideia griega. Madrid: Fondo de Cultura Económica.

Jager, W. (1995). Paideia. México: Fondo de Cultura Económica.

Jaramillo Vélez, R. (2004). Problemática actual de la democracia. Bogotá: Ediciones Jurídicas Gustavo Ibáñez.

Kafka, F. (1983). Obras completas. Tomo IV. Buenos Aires: Visión Libros.

Kant, E. (1989). Respuesta a la pregunta ¿Qué es la ilustración? Madrid: Tecnos.

Kaufmann, D. (2000). Corrupción y reforma institucional: el poder de la evidencia empírica. Revista Perspectivas, 3(2). Chile: Universidad de Chile.

Kennedy, J. F. (1956). Profiles in courage. Nueva York: Harper y Bros.

Latorre Iglesias, E. L. (2010). La crisis de la esfera pública: privatización y alienación en el mundo moderno. Revista Verbum, (6). Santa Marta: Universidad Sergio Arboleda.

Latorre Iglesias, E. L. (2011). Reseña: Ios principios del gobierno representativo. Revista Prolegómenos-Derechos y Valores (pp. 291293). Bogotá: Universidad Militar Nueva Granada. 
Latorre Iglesias, E. L. (2015). Litigio estructural y experimentalismo jurídico. Bogotá: Fondo de publicaciones Universidad Sergio Arboleda.

Locke, J. (1988). Ensayo sobre el gobierno civil. Madrid: Alianza Editorial.

Lope De Vega, F. (1999). Fuente Ovejuna. Madrid: Folio.

López, C. (2007). La ruta de la expansión paramilitar y la transformación política en Antioquia 1007 a 2007. En M. Romero (Ed.), Parapolítica, la ruta de la expansión paramilitar y los acuerdos políticos (p. 123). Ciudad: Bogotá D.C.: Intermedio Editores.

Lyotard, J. F. (2006). La condición postmoderna. Barcelona: Cátedra.

Manin, B. (2006). Los principios del gobierno representativo. Madrid: Alianza Editorial.

Maquiavelo, N. (1999). El príncipe. Santa Fe de Bogotá: Panamericana Editorial.

Martel, F. (2011). Cultura Mainstream: cómo nacen los fenómenos de masas. Barcelona: Taurus.

Mejía Quintana, Ó. (2002). Dominación y exclusión en la Constitución de 1991. La constitucionalidad de la mentira. Revista Palimpsesto. UNAL-2.

Mercado Pacheco (2012). Experimentalismo democrático, nuevas formas de regulación y legitimación del derecho. Granada: Universidad de Granada.

Mina Paz, Á. (2005, julio). Participación ciudadana en Colombia. Revista Aportes Andinos, (14). Cali: Universidad del Valle.

Mineros S.A. (2009). Memorias de sostenibilidad. En: http://www.mineros.com.co/pdf/ MemoriaSostenibilidad2009.pdf

Miralles, A. M. (2007). Periodismo, opinión pública y agenda ciudadana. Bogotá: Grupo Editorial Norma.

Mitchells, R. (2008). Los partidos políticos. Buenos Aires: Amorrortu.

Mockus, A. (1994). Anfibios culturales, moral y productividad. Revista Colombiana de Psicología, (3), 125-135.

Moncada Roa, P. y otros (2007). Los Estados fallidos o fracasados. Bogotá: Siglo del Hombre Editores, Universidad de los Andes, Pontificia Universidad Javeriana.

Naim, M. (2013). El fin del poder: empresas que se hunden, militares derrotados, Papas que renuncian y gobiernos impotentes. Cómo el poder ya no es lo que era. Barcelona: Debate.

Nun, J. (2004). Estado y ciudadanía. México: PNUD.

Nussbaum, M. (2011). Sin fines de lucro: por qué la democracia necesita las humanidades. Buenos Aires: Katz. 
Ohmae, K. (2007). El nuevo escenario global. Bogotá: Grupo Editorial Norma.

Ostrom, E. (2000). El gobierno de los bienes comunes. La evolución de las instituciones. México: UNAM-CRIM. FCE.

Parsons, T. (1982). El sistema social. Madrid: Alianza Editorial.

Periódico El Colombiano. "Macaco" confesó otros 45 asesinatos, 11 de diciembre de 2007.

Periódico Portafolio, marzo 12 de 2014.

Rawls, J. (2006). Teoría de la justicia. México: Fondo de Cultura Económica.

República de Colombia. Constitución Política de 1991. Bogotá: Legis.

República de Colombia. Ministerio del Interior y de Justicia (2011). Estatuto anticorrupción. Bogotá: Imprenta Nacional.

Revista Semana (1985). El oro con sangre entra: En El Bagre, el paro cívico ha desembocado en militarización y muertos, 01 de abril de 1985. En http://www.semana.com/ economia/articulo/el-oro-con-sangre-entra/6355-3

Revista Semana (1998). La guerra de San Lucas, 26 de octubre de 1998: en http://www. semana.com/nacion/articulo/la-guerra-desan-lucas/37463-3
Revista Semana (2014). Por qué las instituciones están en crisis. En http://www.semana.com/nacion/articulo/instituciones-encrisis/409100-3

Rifkin, J. (2000). La era del acceso: la revolución de la nueva economía. Barcelona: Paidós.

Ritzer, G. (2007). Los tentáculos de la McDonalización. Madrid: Editorial Popular.

Robinson, J. (2014). La realidad colombiana. En M. T. Ronderos, Guerras recicladas. Bogotá: Aguilar.

Rodríguez Zepeda, J. (2004). Estado y transparencia: un paseo por la filosofía política. México: Instituto Federal de Acceso a la Información Pública.

Sandel, M. (2011). Justicia: chacemos lo que debemos? Barcelona: Debate.

Sandel, M. (2013). Lo que el dinero no puede comprar: los límites morales del mercado. Barcelona: Debate.

SIMCO, Sistema de Información Minero Colombiano (2014). http://www.upme.gov. co/generadorconsultas/Consulta_Series. aspx idModulo=4\&tipoSerie=116\&grupo $=357 \&$ Fechainicial=01/01/2004\&Fechafin $\mathrm{al}=31 / 12 / 2014$

Simmel, G. (2002). Cuestiones fundamentales de sociología. Barcelona: Gedisa. 
Sistema de Participación Ciudadana, SIPAR Uribe, M. T. (2001). Nación, soberano y ciu(2014). Contraloría General de la República. dadano. Medellín: Corporación Región.

Sudarsky, J. (1998). El capital social en Co-

Uribe, M. T. (2002). Las promesas incumplilombia. Bogotá: DANE. das de la democracia participativa. En V. M. Moncayo y otros, El debate a la Constitución. Tassin, E. (2012). La manifestación polítiBogotá: Universidad Nacional de Colombia ca: más allá del acierto y del fracaso. En L. ILSA. Quintana \& J. Vargas (2012). Hannah Arendt: política, violencia, memoria. Bogotá: Universidad de los Andes.

Velásquez, F. (2003). ¿Qué ha pasado con la participación ciudadana en Colombia? Bogotá: Fundación Corona.

Transparencia por Colombia (2013). Informe anual. Bogotá.

Zizek, S. (2011). Entrevista en el diario El País. El País, lunes 25 de abril de 2011. 